Article

\title{
Sasa quelpaertensis Leaf Extract Inhibits Colon Cancer by Regulating Cancer Cell Stemness in Vitro and in Vivo
}

\author{
Soo Jin Min ${ }^{1}$, Ji Ye Lim ${ }^{1}$, Haeng Ran Kim ${ }^{2}$, Se-Jae Kim ${ }^{3}$ and Yuri Kim ${ }^{1, *}$ \\ 1 Department of Nutritional Science and Food Management, Ewha Womans University, \\ Seoul 120-750, Korea; E-Mails: 009267@naver.com (S.J.M.); godlovesme86@hanmail.net (J.Y.L.) \\ 2 National Academy of Agricultural Science, Rural Development Administration, \\ Jeollabuk-do 565-851, Korea; E-Mail:kimhrr@korea.kr \\ 3 Department of Biology, Jeju National University, Jejusi, Jeju 690-756, Korea; \\ E-Mail: jejusasa@naver.com
}

* Author to whom correspondence should be addressed; E-Mail: yuri.kim@ewha.ac.kr; Tel.: +82-2-3277-4485; Fax: +82-2-3277-2862.

Academic Editor: Sanjay K. Srivastava

Received: 6 March 2015 / Accepted: 24 April 2015 / Published: 30 April 2015

\begin{abstract}
A rare subpopulation of cancer cells, termed cancer stem cells (CSCs), may be responsible for tumor relapse and resistance to conventional chemotherapy. The development of a non-toxic, natural treatment for the elimination of CSCs is considered a strategy for cancer treatment with minimal side effects. In the present study, the potential for Sasa quelpaertensis leaf extract (SQE) and its two bioactive compounds, tricin and $p$-coumaric acid, to exert anti-CSC effects by suppressing cancer stemness characteristics were evaluated in colon cancer cells. CD $133^{+} \mathrm{CD} 44^{+}$cells were isolated from HT29 and HCT116 cell lines using flow-activated cell sorting (FACs). SQE treatment was found to significantly suppress the self-renewal capacity of both cell lines. SQE treatment was also associated with the down-regulation of $\beta$-catenin and phosphorylated GSK3 $\beta$, while significantly enhancing cell differentiation by up-regulating CK20 expression and blocking the expression of several stem cell markers, including DLK1, Notch1, and Sox-2. In vivo, SQE supplementation suppressed tumor growth in a xenograft model by down-regulating stem cell markers and $\beta$-catenin as well as HIF-1 $\alpha$ signaling. Compared with two bioactive compounds of SQE, SQE exhibited the most effective anti-CSC properties. Taken together, these results provide evidence that $\mathrm{SQE}$ inhibits colon cancer by regulating the characteristics of CSCs.
\end{abstract}


Keywords: Sasa quelpaertensis Nakai leaf extract; colon cancer; cancer stem cells; self-renewal; differentiation

\section{Introduction}

Worldwide, colon cancer is one of the most common types of cancer diagnosed, and it is a major cause of cancer-related morbidity and mortality in both men and women. Colon cancer is responsible for 1.4 million new cases and nearly 700,000 deaths worldwide [1]. Despite advances in the screening used for colon cancer and the emergence of new targeted therapeutic combinations, nearly $50 \%$ of colon cancer patients experience recurrence. Thus, it is hypothesized that colon cancer is driven by a rare-subpopulation of self-renewing cancer cells, termed cancer stem cells (CSCs) [2]. Accordingly, failure to eliminate CSCs may be critical for metastasis and cancer relapse following therapeutic treatment [3]. Therefore, targeting of CSCs may represent a key therapeutic strategy for the complete treatment of diseases that are maintained by these CSC populations.

In most cases, CSCs have been identified based on their expression of specific cell surface markers, including CD133, CD44, and aldehyde dehydrogenase (ALDH1). CD133 (also known as prominin-1) is a type I transmembrane glycoprotein that has been characterized as a cell surface marker of CSCs [4]. O'Brian and colleague were the first to demonstrate that only a small subset of CSCs isolated from a $\mathrm{CD}_{133^{+}}$population were capable of growing as clonospheres in serum-free sphere media, and these cells could initiate tumor growth in a serial xenograft mouse model [5]. CD133 ${ }^{+}$cells have also been found to maintain long-term expression of CD133 when grown in sphere media [6]. CD44 is a hyaluronan receptor that plays a critical role in the homing and colonization of adult stem cells, CSCs, and metastasizing cancer cells [7]. Similarly, single CD44 ${ }^{+}$colon cancer cells have been shown to form spheres in serum-free sphere media and have been used to establish xenograft tumor models in vivo [8]. Consequently, CD44 has been reported to be a marker for colon CSCs. While colon cancer cells express both CD133 and CD44, the presence of these markers alone is probably insufficient to identify CSCs [9]. Furthermore, cells expressing $\mathrm{CD}_{133^{+}}$and $\mathrm{CD}_{4} 4^{+}$have exhibited greater tumorigenicity than cells expressing either marker alone [10]. Taken together, these results suggest that a combination of markers are needed to identify the CSC population in human colon cancer cells.

CSCs have the capacity to undergo pluripotent differentiation, self-renewal, and tumorigenicity, and these can lead to resistance to chemotherapy $[11,12]$. Induction of terminal differentiation to inhibit self-renewal may represent a valid treatment option for eliminating CSCs. A number of stem cell markers are expressed by CSCs. Of these, Drosophila delta-like 1 homologue (DLK1) is a member of the epidermal growth factor-like homeotic protein family and has been reported to regulate the differentiation of adipocytes, hematopoietic stem cells, and neuronal and hepatic CSCs [13,14]. SRY-related HMG-box-2 (Sox-2) is a gene that plays a role in the maintenance of a progenitor state and its transcription has been detected in all of the tumors tested to date [15]. Another stem cell marker, Notch homolog 1 (Notch1), has a fundamental role in regulating proliferation of CSCs [16].

$\mathrm{Wnt} / \beta$-catenin signaling is one of the key pathways involved in the transformation of normal colonic epithelial cells into colon cancer cells and self-renewing CSCs [17,18]. Briefly, translocation 
of $\beta$-catenin into the nucleus leads to its binding of $\mathrm{T}$ cell factor/lymphoid enhancer factor (TCF/LEF) and the activation of Wnt target genes [18]. Glycogen synthase kinase-3 $\beta$ (GSK3 $\beta$ ) phosphorylates $\beta$-catenin to regulate its levels of expression via ubiquitination and targeted degradation [19]. Hypoxia further increases the clonogenicity of tumor cells and the intrinsic tumorigenic potential of tumor cells by arresting tumorigenic cells in their undifferentiated state and maintaining their stem cell potential [20]. Hypoxia-inducible factor-1 (HIF-1) is a critical regulator of the tumor cell response to hypoxia, and it consists of an oxygen-dependent $\alpha$-subunit (HIF-1 $\alpha$ ) and an oxygen-independent $\beta$-subunit (HIF-1 $\beta$ ). Upon stabilization of the $\alpha$-subunit, HIF- $1 \alpha$ translocates to the nucleus and activates various genes, including vascular endothelial growth factor (VEGF) [21]. Thus, regulation of CSCs and hypoxic cancer cells may represent a more efficient therapeutic strategy for the targeting of highly resistant cancers.

Sasa (poaceae), known as bamboo grass, is widely grown in Asian countries, including Korea, China, and Japan [22]. Sasa leaves are commonly considered to be beneficial for diabetes, obesity, ulcers, inflammation, and cancer [23-25]. Previously, various Sasa species and their bioactive compounds have been shown to exhibit anti-cancer and anti-tumor properties [24,26,27]. For example, Sasa kumaizawa extract has been shown to mediate immunopotentiating and cancer preventive effects in a 7,12-dimethylbenz[ $\alpha$ ]anthracene (DMBA)-induced rat tumor model [28]. In SHN mice, an anti-mammary tumor effect following treatment with an alkaline extract of Sasa senanensis Rehder (also known as Sasa Health) was observed [29]. Sasa quelpaertensis Nakai is native to Korea and is only grown on Mt. Halla (Jeju Island, Korea) [30]. Sasa quelpaertensis leaves contain a mixture of polysaccharides and polyphenols, including $p$-coumaric acid and tricin, which may mediate the anticancer effects observed for Sasa quelpaertensis extracts (SQE) [25,31]. Byun et al. [32] have recently reported an pro-apoptotic effect for Sasa quelpaertensis Nakai on HT29 colon cancer cells, while an anti-cancer effect was observed following the treatment of lung cancer cells with a combination of Sasa quelpaertensis Nakai leaf extract and cisplatin [30]. However, there is little known about the role of SQE and its bioactive compounds in mediating or inducing the differentiation, self-renewal capacity, and tumorigenicity of colon CSCs. Therefore, the aim of the present study was to investigate the effects of SQE on characteristics of colon CSCs.

\section{Results and Discussion}

\subsection{Isolation of $\mathrm{CD} 133^{+} \mathrm{CD} 44^{+} \mathrm{HT29}$ and $\mathrm{CD} 133^{+} \mathrm{CD} 44^{+} \mathrm{HCT1} 16$ Cells by FACS (Flow-Activated Cell Sorting)}

Expression of the CSC markers, CD133 and CD44, were analyzed by FACS. CD133 ${ }^{+}$CD $44^{+}$ double-stained cells were isolated from both HT29 and HCT116 cell lines and this subpopulation was more than $70 \%$ for each cell line. According to their fluorescence intensity values, , the top $20 \%$ of the isolated cells with the highest fluorescence intensities of the isolated cells were designated $\mathrm{CD} 33^{+} \mathrm{CD} 44^{+} \mathrm{CSCs}$, while $20 \%$ of the cells with the lowest fluorescence intensities of the isolated cells were used as control cells for further experiments (Figure 1A,B). 
A

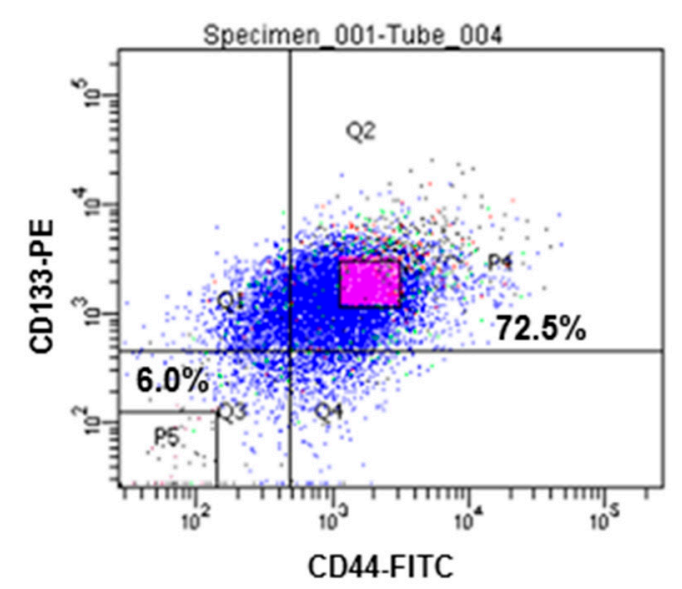

B

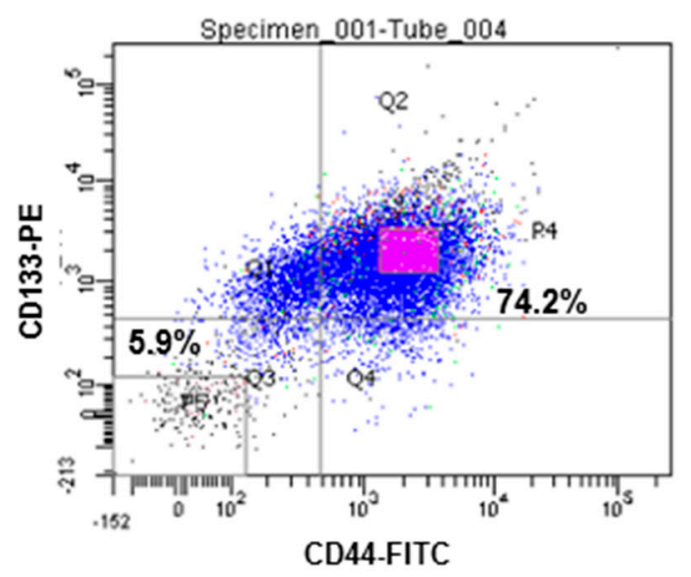

Figure 1. Isolation of $\mathrm{CD} 133^{+} \mathrm{CD} 44^{+} \mathrm{HT} 29$ and $\mathrm{CD} 133^{+} \mathrm{CD} 44^{+} \mathrm{HCT} 116$ cells by FACS. Expression of the CSCs markers, CD133 and CD44, was calculated using flow cytometry (A) HT 29 cells; (B) HCT 116 cells.

\subsection{Effects of SQE (Sasa quelpaertensis Leaf Extract), p-Coumaric Acid, and Tricin on the Self-Renewal Characteristics of Colon CSCs (Cancer Stem Cells)}

One of the significant characteristics of CSCs is the capacity for self-renewal. Clonogenic assays are used to analyze the ability of a single cell to form a colony, a process which requires reproductive integrity and represents the self-renewal potential of CSCs [14]. When HT29 cells were treated with various concentrations of $\operatorname{SQE}(0,100,200$, or $300 \mu \mathrm{g} / \mathrm{mL})$, as well as $p$-coumaric acid and tricin at concentrations equivalent to $300 \mu \mathrm{g} / \mathrm{mL} \mathrm{SQE}$, for eight days, clonogenic formation was suppressed in the presence of 200 and $300 \mu \mathrm{g} / \mathrm{mL}$ SQE (59.6\% and 95.2\% compared to control cells; $p<0.001$ and $p<0.001$, respectively). $p$-Coumaric acid and tricin also tended to suppress colony formation, although the differences were not statistically significant (Figure 2Aa). For the HCT116 cells, SQE treatment inhibited colony formation in a dose-dependent manner $(p<0.01)$, while $p$-coumaric acid and tricin only weakly inhibited colony formation (Figure 2Ab).

Another widely used assay to analyze the self-renewal capacity of CSCs is the sphere formation assay. In this assay, the ability of cells to grow as non-adherent spheroids in serum-free CSC medium is examined [33]. In the present study, treatment with SQE, $p$-coumaric acid, and tricin resulted in a marked decrease in the size and number of the spheres that formed compared with untreated HT29 and HCT 116 cells (Figure 2B). The greatest disruption of sphere formation was observed in the presence of $300 \mu \mathrm{g} / \mathrm{mL} \mathrm{SQE}$, and this resulted in a $62.9 \%$ and $65.1 \%$ reduction in sphere formation in HT29 cells and HCT 116 cells, respectively ( $p<0.001$ and $p<0.001$, respectively). Taken together, these results suggest that $\mathrm{SQE}$ was more effective in suppressing the self-renewal capacity of colon CSCs than $p$-coumaric acid or tricin alone. 

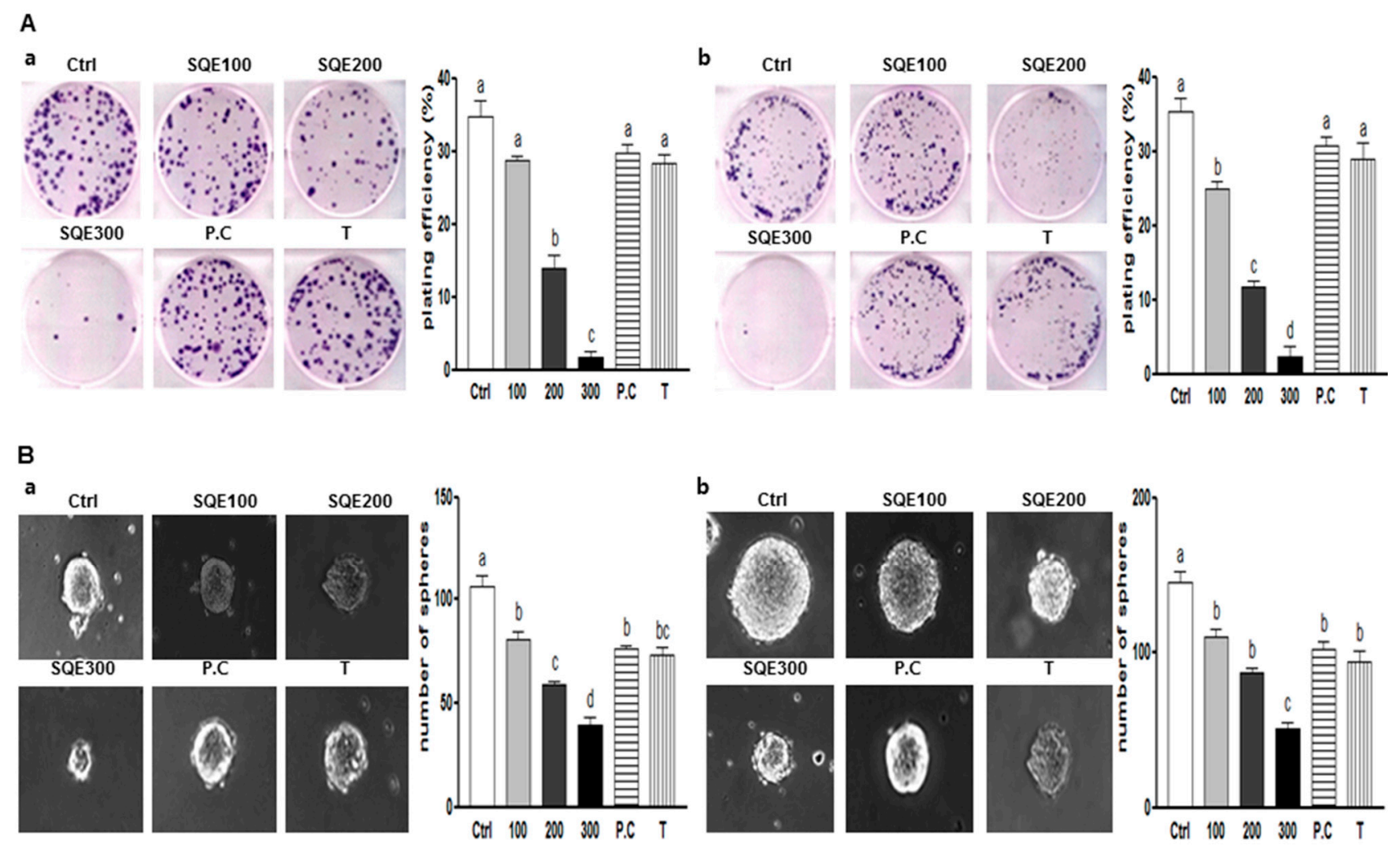

Figure 2. Effects of SQE, $p$-coumaric acid, and tricin on self-renewal characteristics of colon CSCs. CD133 ${ }^{+} \mathrm{CD} 44^{+} \mathrm{HT} 29$ cells (a) and $\mathrm{CD} 133^{+} \mathrm{CD} 44^{+} \mathrm{HCT} 116$ cells (b) were treated with $\operatorname{SQE}(0,100,200$, or $300 \mu \mathrm{g} / \mathrm{mL})$, or $p$-coumaric acid $(1.8 \mu \mathrm{M})$ and tricin $(0.7 \mu \mathrm{M})$ at concentrations equivalent to that contained in $300 \mu \mathrm{g} / \mathrm{mL}$ SQE. (A) After eight days, the resulting colonies were fixed and stained. Microscopy images of colony formation were obtained (magnification, 100×, left panel) and the number of colonies was recorded (right panel). Plating efficiency $(\%)=$ (number of colonies) $/($ total cell number $) \times 100$; (B) Sphere formation was analyzed for both cell lines and images were obtained with phase contrast microscopy (left panel, magnification, 100×). The number of spheres was recorded (right panel). The letter labels on the histogram indicate the values that significantly differed from each other $(p<0.05)$ according to one-way ANOVA for multiple comparisons. Ctrl, Control; SQE, Sasa quelpaertensis extract; P.C, p-coumaric acid; T, tricin.

\subsection{Effects of SQE, $p$-Coumaric Acid, and Tricin on Wnt/ $\beta$-Catenin Signaling}

The Wnt/ $\beta$-catenin signaling pathway is critical for promoting the self-renewal capacity of CSCs and it helps maintain normal colon stem cells [34]. To investigate the mechanisms that may contribute to the effect of SQE on the self-renewal capacity of colon CSCs, expression of $\beta$-catenin was examined. As shown in Figure 3, SQE treatment down-regulated expression of $\beta$-catenin in both cell lines. In particular, $300 \mu \mathrm{g} / \mathrm{mL}$ SQE significantly down-regulated levels of $\beta$-catenin by up to $55.9 \%$ in HT29 cells and by $40.8 \%$ in HCT116 cells compared to control cells (Figure 3; $p<0.001$ and $p<0.001$, respectively). $p$-Coumaric acid and tricin also significantly down-regulated both cytosolic and nuclear $\beta$-catenin expression, albeit less effectively than SQE $(p<0.001$ and $p<0.001$, respectively). 
A

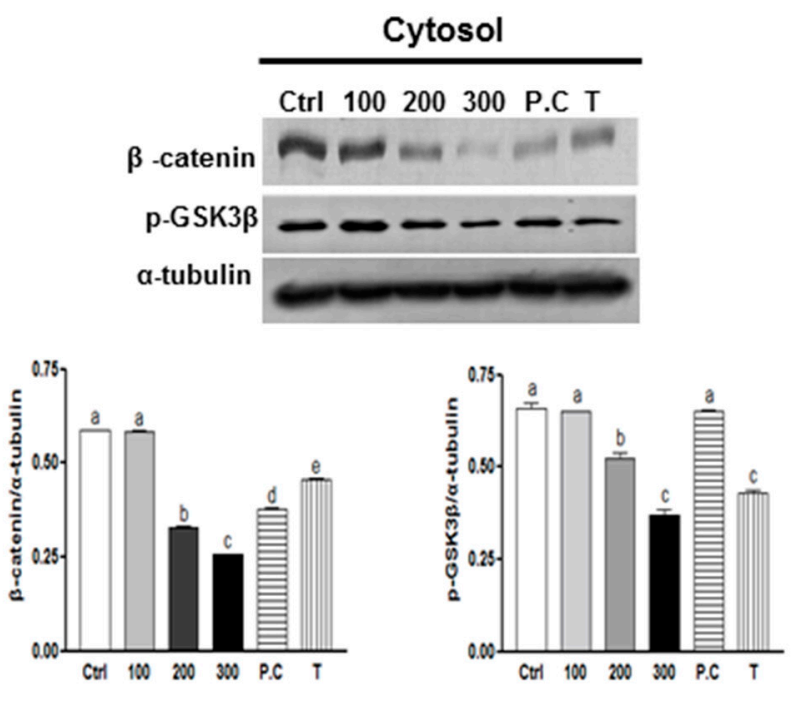

B

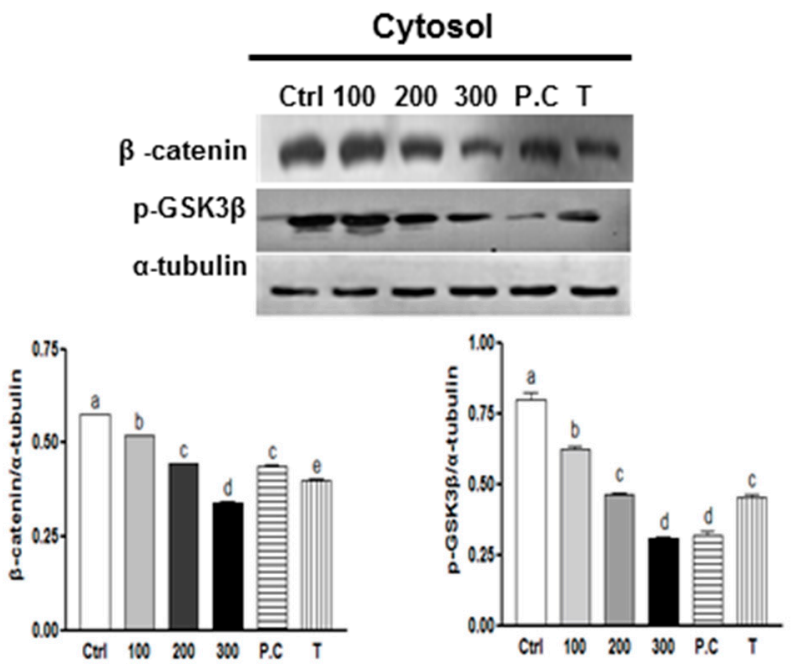

Nuclear
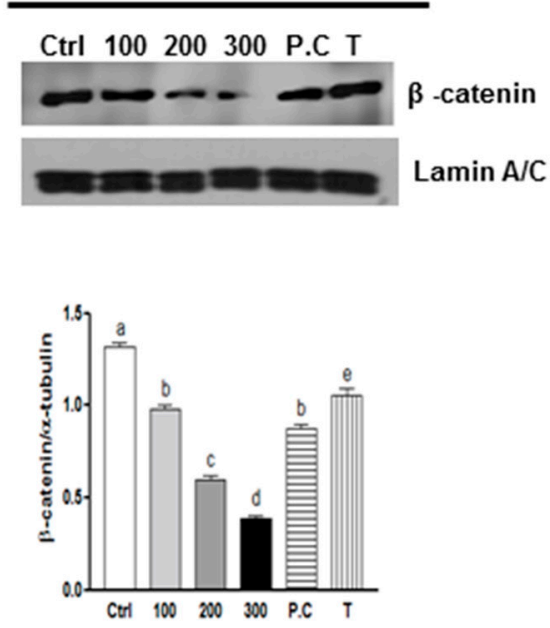

Nuclear
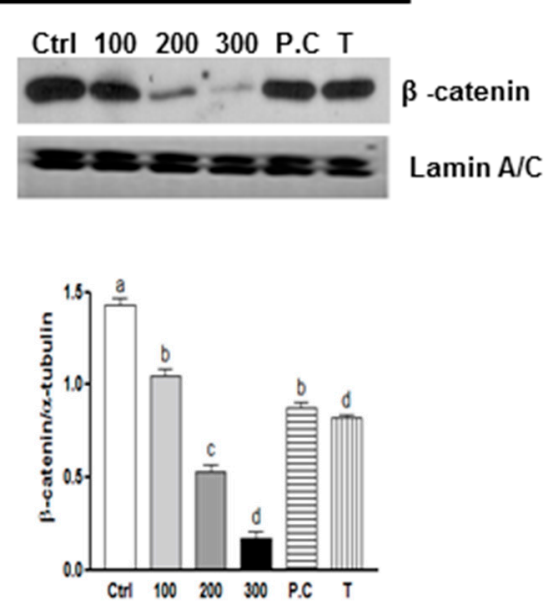

Figure 3. Effects of SQE, p-coumaric acid, and tricin on Wnt/ $\beta$-catenin signaling. Expression levels of $\beta$-catenin and $p$-GSK3 $\beta$ were examined using Western blot assays in HT 29 cells (A) and HCT 116 cells (B), and detection of $\alpha$-tubulin and Lamin A/C were used as loading controls. The letter labels on the histogram indicate the values that significantly differed from each other $(p<0.05)$ according to one-way ANOVA for multiple comparisons. Ctrl, Control; SQE, Sasa quelpaertensis extract; P.C, p-coumaric acid; $\mathrm{T}$, tricin.

GSK3 $\beta$ modulates levels of intracellular $\beta$-catenin by promoting ubiquitin-targeted degradation of $\beta$-catenin [35]. Phosphorylation of GSK3 $\beta$ at Ser9 leads to a decreased activity of this enzyme, which leads to stabilized levels of $\beta$-catenin [36]. In the present study, a decreased in phosphorylation of GSK3 $\beta$ from $43.8 \%$ and $62.2 \%$ was detected in cells from both cell lines that were treated with $300 \mu \mathrm{g} / \mathrm{mL}$ SQE. Tricin treatment also decreased the levels of GSK3 $\beta$ phosphorylation (Figure 3). Taken together, these results indicate that SQE is highly effective in decreasing the self-renewal capacity of colon CSCs by inactivating GSK3 $\beta$ phosphorylation at Ser9, thereby leading to $\beta$-catenin degradation. 


\subsection{Effects of SQE, p-Coumaric Acid, and Tricin on Cell Differentiation in Colon CSCs}

Another important characteristic of CSCs is their capability to undergo differentiation [3]. To evaluate the capacity for SQE, $p$-coumaric acid, and tricin to induce cell differentiation, expression of CK20, a differentiation marker of colon CSCs [37], was examined in $\mathrm{CD} 133^{+} \mathrm{CD} 44^{+}$cells isolated from HT29 and HCT116 cell lines. The effect of SQE on the differentiation of colon CSCs was also examined by treating cells with various concentrations of SQE, $p$-coumaric acid, and tricin for eight days. In both cell lines, treatment with SQE resulted in an increase in expression levels of CK20 (Figure 4). However, treatment with $p$-coumaric acid and tricin only increased expression levels of CK20 in the HT29 cells (Figure 4A).

A

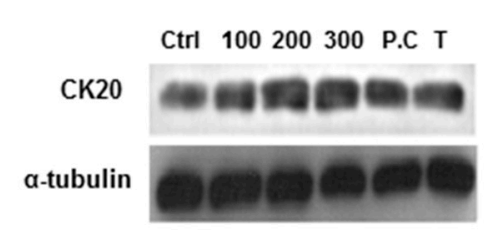

B

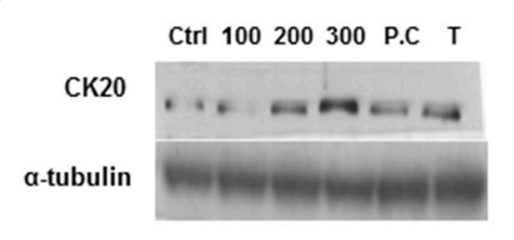

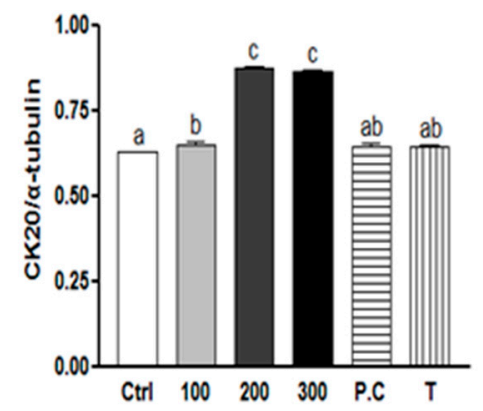

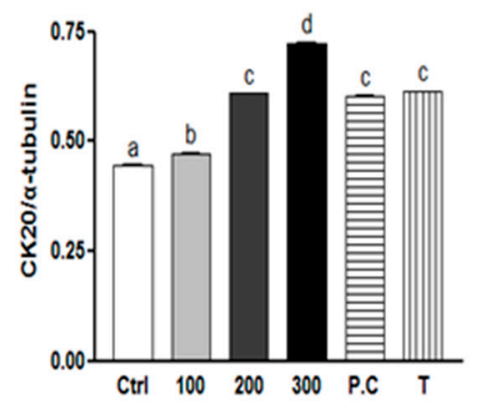

Figure 4. Effects of SQE, $p$-coumaric acid, and tricin on cell differentiation in colon CSCs. CD133 ${ }^{+} \mathrm{CD}_{4} 4^{+} \mathrm{HT} 29$ cells (A) and $\mathrm{CD} 133^{+} \mathrm{CD} 44^{+}$HCT116 cells (B) were treated with $\operatorname{SQE}(0,100,200$, or $300 \mu \mathrm{g} / \mathrm{mL})$, or $p$-coumaric acid $(1.8 \mu \mathrm{M})$ and tricin $(0.7 \mu \mathrm{M})$ at concentrations equivalent to that contained in $300 \mu \mathrm{g} / \mathrm{mL} \mathrm{SQE}$. Levels of protein expressions for Cytokeratin 20 (CK20) were examined by Western blot analysis, and detection of $\alpha$-tubulin was used as a loading control. The letter labels on the histogram indicate the values that significantly differed from each other $(p<0.05)$ according to one-way ANOVA for multiple comparisons. Ctrl, Control; SQE, Sasa quelpaertensis extract; P.C, $p$-coumaric acid; T, tricin.

\subsection{Effects of SQE, p-Coumaric Acid, and Tricin on the Expression of Stem Cell Markers and VEGF (Vascular Endothelial Growth Factor) in Colon CSCs}

The primary objective of the current study was to determine whether SQE can eliminate colon CSCs. To accomplish this objective, mRNA levels of stem cell markers, including CD133, CD44, DLK1, Notch1, Sox-2, and VEGF (a potent growth factor for blood vessel endothelial cells [38]) were 
assayed using real-time PCR. The expressions of all six markers were significantly down-regulated at all doses of SQE, $p$-coumaric acid, and tricin in both CD133 ${ }^{+} \mathrm{CD} 44^{+}$HT29 and HCT116 cells (Figure 5). These results suggest that SQE and its bioactive compounds, $p$-coumaric acid and tricin, are highly effective in suppressing CSC markers and in eliminating CD133 ${ }^{+} \mathrm{CD} 44^{+} \mathrm{HT} 29$ and HCT116 cells.

A

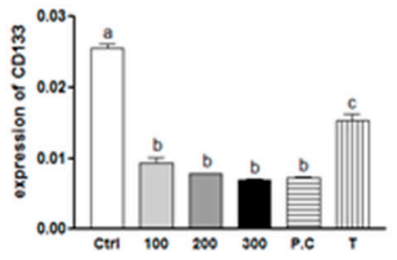

d

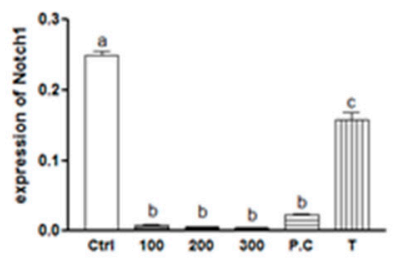

B
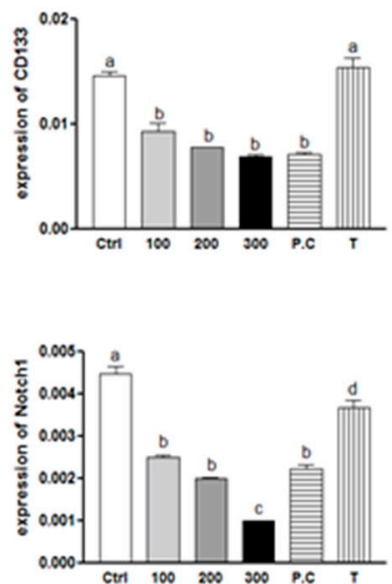

b

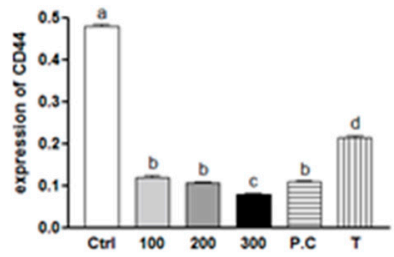

e

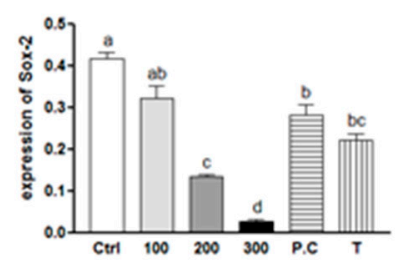

b

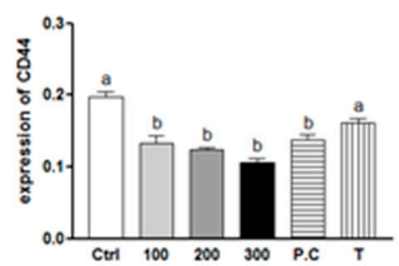

e

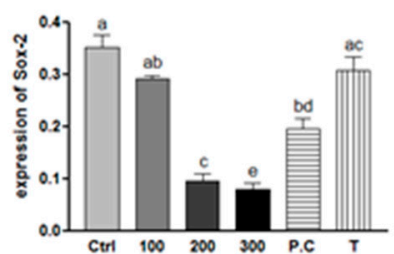

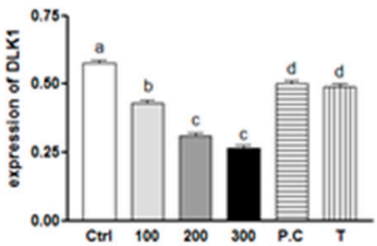

f

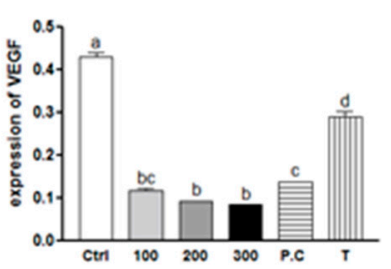

C

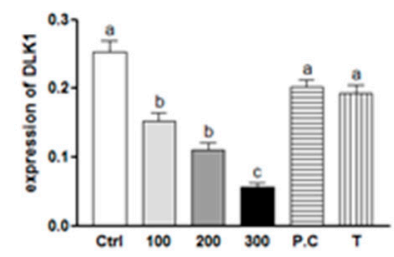

f

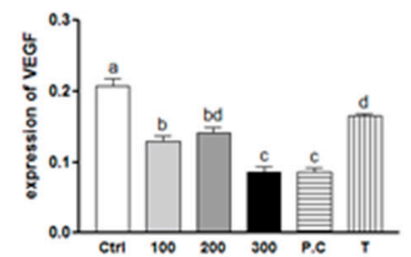

Figure 5. Effects of SQE, p-coumaric acid, and tricin on mRNA levels of CD133, CD44, DLK1, Notch1, Sox-2, and VEGF in colon CSCs. CD133 CD44 ${ }^{+}$HT29 cells (A) and CD133 ${ }^{+}$CD $44^{+}$HCT116 cells $(\mathbf{B})$ were treated with SQE $(0,100,200$, or $300 \mu \mathrm{g} / \mathrm{mL})$, or $p$-coumaric acid $(1.8 \mu \mathrm{M})$ and tricin $(0.7 \mu \mathrm{M})$ at concentrations equivalent to that contained in $300 \mu \mathrm{g} / \mathrm{mL}$ SQE. Levels of mRNA for (a) CD133; (b) CD44; (c) DLK1; (d) Notch1; (e) Sox-2; and (f) VEGF were examined using real-time PCR, with detection of $\beta$-actin used as an internal control. The letter labels on the histogram indicate the values that significantly differed from each other $(p<0.05)$ according to one-way ANOVA for multiple comparisons. Ctrl, Control; SQE, Sasa quelpaertensis extract; P.C, p-coumaric acid; T, tricin.

To investigate whether SQE, $p$-coumaric acid, and tricin suppress protein expression levels of several well-known CSC markers were assayed, including DLK1, Notch 1, and Sox-2 and VEGF 
following treatment with SQE, p-coumaric acid, or tricin. Treatment with SQE down-regulated expression levels of these markers in both $\mathrm{CD} 133^{+} \mathrm{CD} 44^{+}$cells isolated from the HT29 and HCT116 cells (Figure 6). In comparison, $p$-coumaric acid and tricin were less effective at down-regulating the stem cell markers assayed compared with SQE.

A
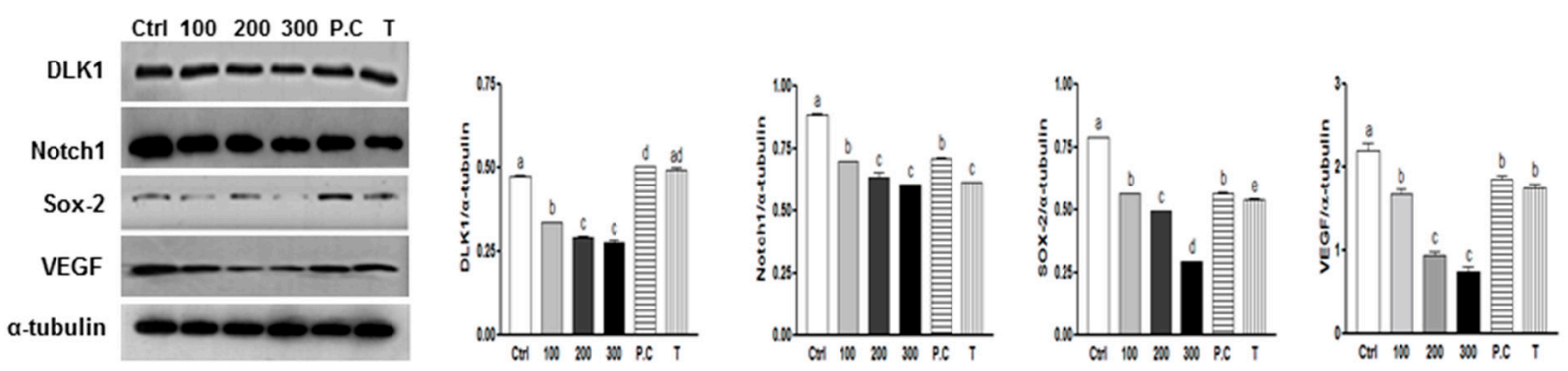

B
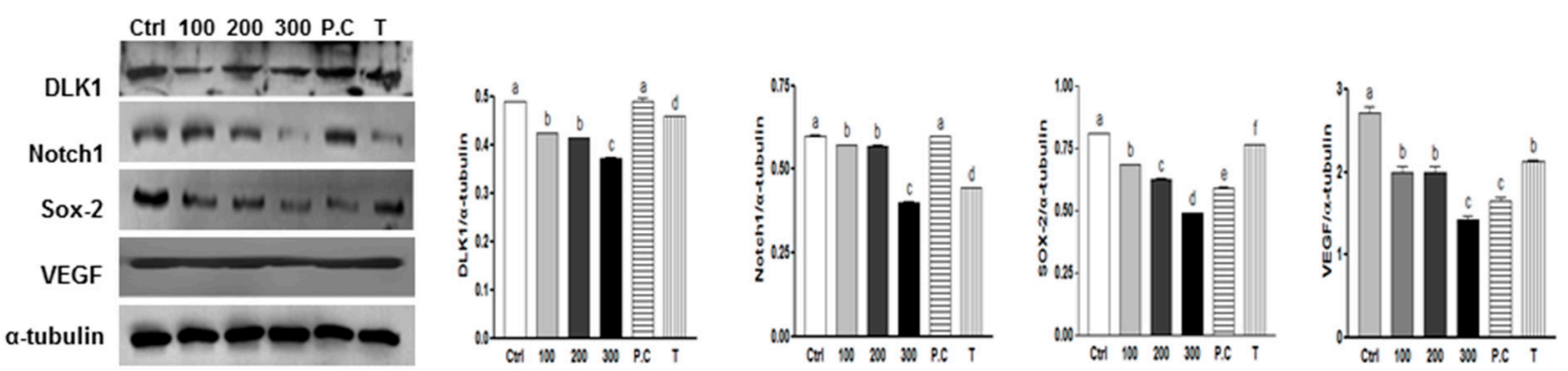

Figure 6. Effects of $\mathrm{SQE}, p$-coumaric acid, and tricin on the protein expression of stem cell markers and VEGF in colon CSCs. CD133 ${ }^{+} \mathrm{CD} 44^{+} \mathrm{HT} 29$ cells (A) and CD133 ${ }^{+} \mathrm{CD} 44^{+}$ HCT116 cells (B) were treated with SQE $(0,100,200$, or $300 \mu \mathrm{g} / \mathrm{mL})$, or $p$-coumaric acid $(1.8 \mu \mathrm{M})$ and tricin $(0.7 \mu \mathrm{M})$ at concentrations equivalent to that contained in $300 \mu \mathrm{g} / \mathrm{mL}$ SQE. Levels of protein expressions for DLK1, Notch1, Sox-2, and VEGF were examined by Western blot analysis, and detection of $\alpha$-tubulin was used as a loading control. The letter labels on the histogram indicate the values that significantly differed from each other $(p<0.05)$ according to one-way ANOVA for multiple comparisons. Ctrl, Control; SQE, Sasa quelpaertensis extract; P.C, p-coumaric acid; T, tricin.

\subsection{Effect of Combination of p-Coumaric Acid and Tricin on Clonogenicity and Stem Cell}

\section{Marker, Notch1}

To investigate the synergism or additive effect between $p$-coumaric acid and tricin in SQE, the combination of $p$-coumaric acid and tricin was treated and then clonogenic capacity and level of one of stem cell markers, Notch 1 was analyzed (Figure 7). Clonogenic formation and Notch 1 expression was suppressed in the presence of $300 \mu \mathrm{g} / \mathrm{mL}$ SQE (89\% compared to control cells; $p<0.001$, respectively). However, combination of $p$-coumaric acid and tricin induced less of an effect compared to SQE or each of the compounds alone. Therefore, these findings confirm that other components of SQE are necessary for the anti-CSC effects of SQE. 
A
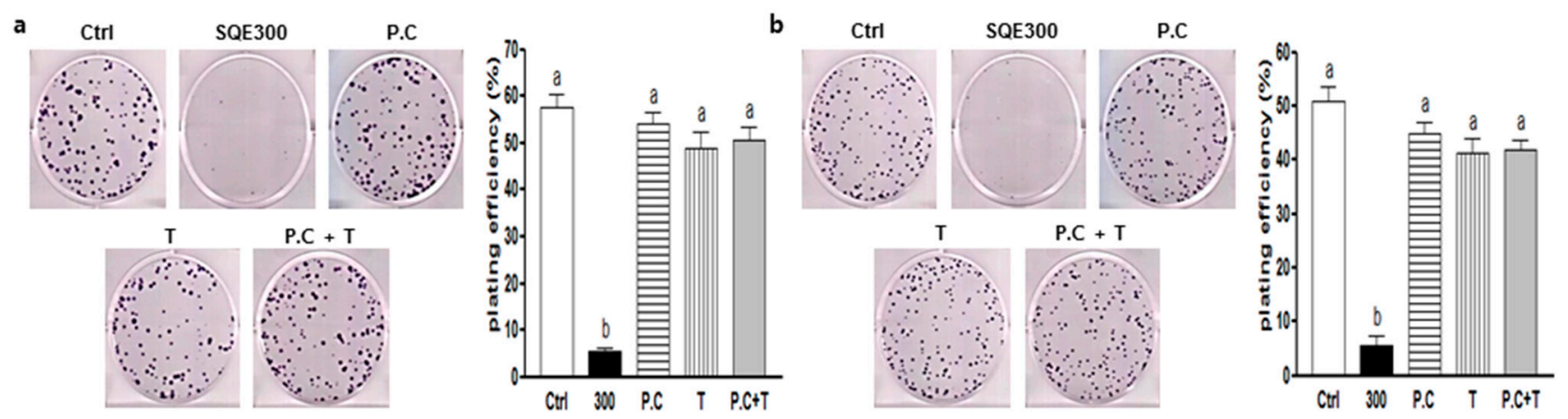

B

a
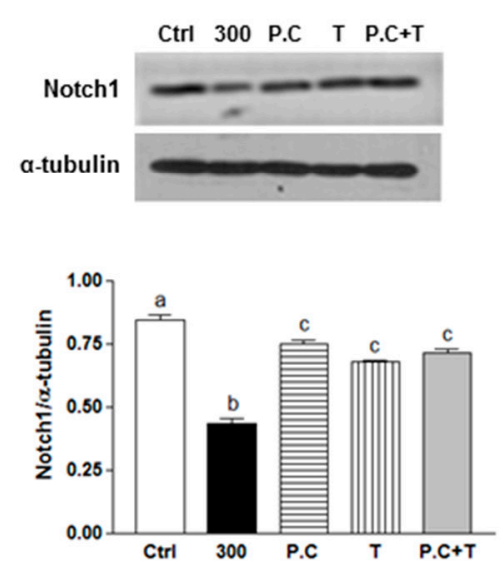

b Ctrl 300 P.C T P.C + T
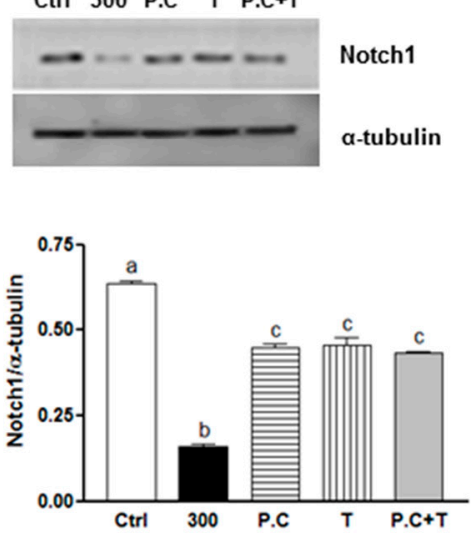

Figure 7. Effect of combination of $p$-coumaric acid and tricin on clonogenicity and stem cell marker, Notch1. CD133 ${ }^{+} \mathrm{CD} 44^{+} \mathrm{HT} 29$ cells (a) and CD133 ${ }^{+} \mathrm{CD} 44^{+} \mathrm{HCT} 116$ cells (b) were treated with $\mathrm{SQE}(300 \mu \mathrm{g} / \mathrm{mL}), p$-coumaric acid $(1.8 \mu \mathrm{M})$, tricin $(0.7 \mu \mathrm{M})$, or combination of $p$-coumaric acid $(1.8 \mu \mathrm{M})$ and tricin $(0.7 \mu \mathrm{M})$. (A) After eight days, the resulting colonies were fixed and stained. Microscopy images of colony formation were obtained (magnification, 100×, left panel) and the number of colonies was recorded (right panel). Plating efficiency $(\%)=($ number of colonies $) /($ total cell number $) \times 100 ;(B)$ Levels of protein expressions for Notch1 was examined by Western blot analysis, and detection of $\alpha$-tubulin was used as a loading control. The letter labels on the histogram indicate the values that significantly differed from each other $(p<0.05)$ according to one-way ANOVA for multiple comparisons. Ctrl, Control; SQE, Sasa quelpaertensis extract; P.C, p-coumaric acid; $\mathrm{T}$, tricin.

\subsection{Effect of SQE on Tumorigenicity and CSC Marker Expression of CD133 ${ }^{+} \mathrm{CD} 44^{+} \mathrm{HT} 29$ Cells in Vivo}

In the present study, SQE treatment was found to inhibit cancer cell stemness in vitro by increasing the expression of differentiation markers and decreasing the expression of CSC markers. When $\mathrm{CD}_{133}{ }^{+} \mathrm{CD} 44^{+} \mathrm{HT} 29$ cells were subcutaneously injected into nude mice, as few as $1 \times 10^{4}$ sorted cells were capable of establishing a tumor within 2 weeks (Figure 8A), thereby demonstrating the CSC potential of these cells. To investigate the anti-tumorigenic effect of SQE supplementation in vivo, 
CD133 ${ }^{+} \mathrm{CD} 44^{+} \mathrm{HT} 29$ cells $\left(1 \times 10^{4} /\right.$ animal $)$ were injected into nude mice. At the time of sacrifice, tumor incidence between the mice that received SQE supplementation and the control mice did not differ (data not shown). However, the mean tumor volume for the SQE supplemented group was $609.8 \pm 226.8 \mathrm{~mm}^{3}$ compared with $1016.7 \pm 722.1 \mathrm{~mm}^{3}$ for the Control group (Figure 8B). This represented a $40.1 \%$ decrease in tumor volume for the SQE treated mice, although this difference was not statistically significant. These data suggest that SQE supplementation weakly inhibits tumor growth in vivo.

A

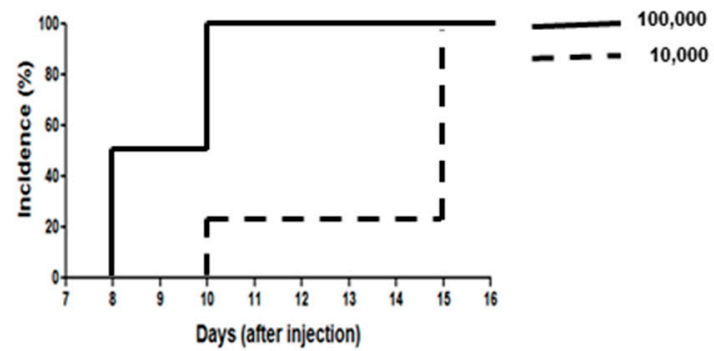

B

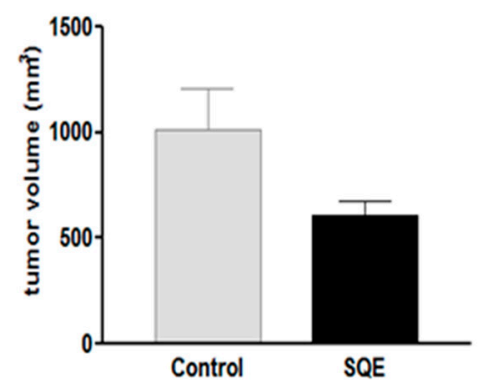

C
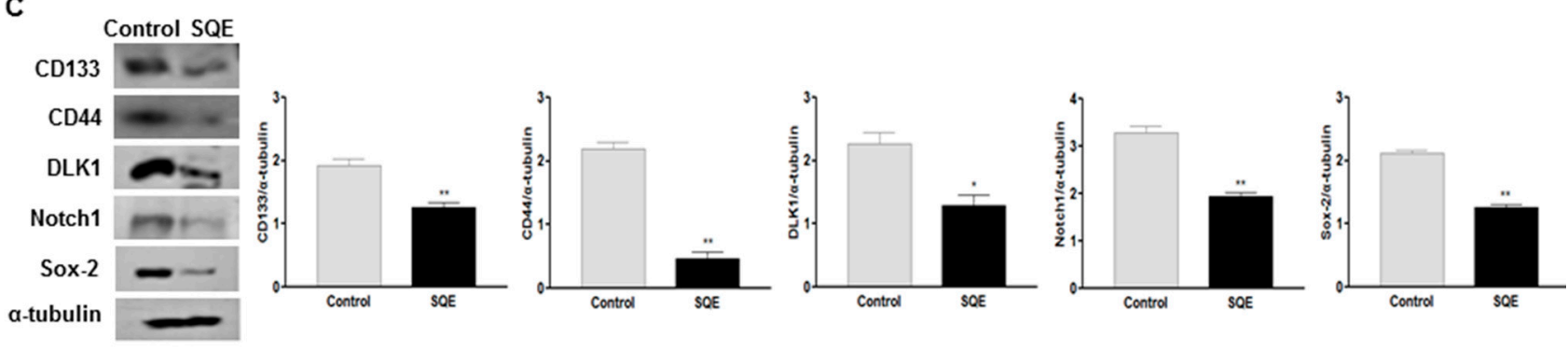

D
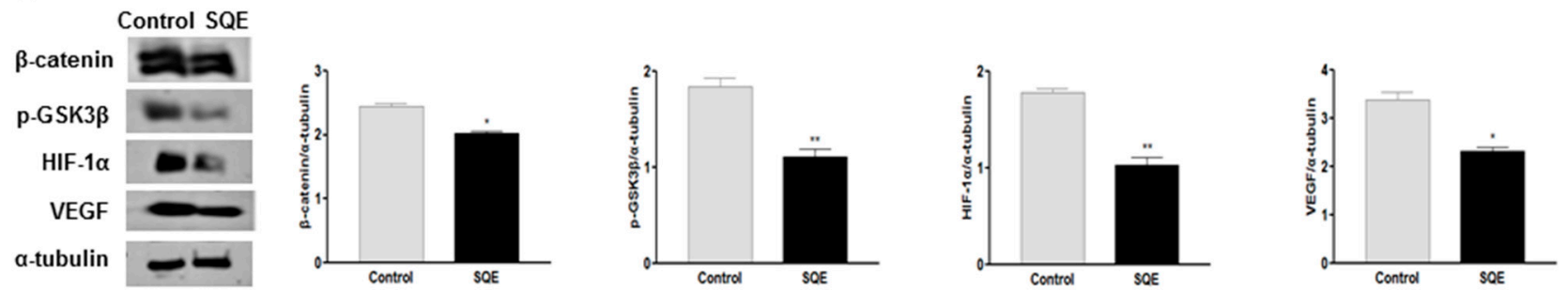

Figure 8. Effect of SQE on tumorigenicity and CSC marker expression of CD133 ${ }^{+} \mathrm{CD} 44^{+}$ HT29 cells in vivo. (A) The tumorigenicity of $\mathrm{CD} 133^{+} \mathrm{CD} 44^{+}$double-sorted cells $(10,000$ or 100,000 cells) was examined following the subcutaneous injection of these cells into nude mice; (B) Tumor volume was measured and compared between the control group and the SQE (300 mg/kg body weight) supplemented group; (C,D) Expression levels of various CSC markers, including CD133, CD44, DLK1, Notch1, and Sox-2 (C), as well as self-renewal and metastasis signaling-related markers, including $\beta$-catenin, $p$-GSK3 $\beta$, HIF-1 $\alpha$, and VEGF (D), were detected by Western blot analysis. Detection of $\alpha$-tubulin was used as a loading control. Representative figures are shown (left panel). Quantification of each protein level was shown with a bar graph. Bar represented the mean \pm SEM. * and ** show significantly difference between two groups by Student's $t$-test $(p<0.05)$. SQE, Sasa quelpaertensis leaf extract. 
To confirm these results, the expression of several CSC markers, including CD133, CD44, DLK1, Notch1, and Sox-2 were analyzed by Western blot. Significantly lower levels of expression were detected for all five targets in the SQE samples (Figure 8C). In addition, SQE samples exhibited 17.1\% lower levels of $\beta$-catenin $(p=0.01)$ and 39.5\% lower levels of phosphorylation of GSK3 $\beta$ at Ser9 $(p<0.004)$ compared with the Control group (Figure 8D).

Hypoxic tumors appear to be highly tumorigenic, poorly differentiated, and they express certain CSC markers $[39,40]$. Expression of HIF-1 $\alpha$ is increased in poorly differentiated cancers and this leads to activation of the HIF-1 $\alpha$ targeted gene, VEGF [21,41]. In the present study, expression levels of HIF- $1 \alpha$ and VEGF were $42.2 \%$ and $31.5 \%$ lower in the SQE supplemented group compared with the Control group, respectively ( $p=0.0012$ and $p=0.0036$, respectively) (Figure 8D). Taken together, these results suggest that SQE suppresses colon cancer tumor growth by suppressing the stemness of the CSC population present and by regulating levels of HIF-1 $\alpha$ and its downstream target gene, VEGF.

\subsection{Discussion}

Despite the availability of surgical resection, radiation, and chemotherapy for the treatment of colon cancer, nearly $50 \%$ of patients develop resistance to treatment and experience tumor relapse or metastasis $[42,43]$. Malignancies originate from a small subset of cancer cells, termed CSCs, and these are capable of initiating and maintaining tumor growth, as well as promoting cell invasion and drug resistance [44]. Thus, the successful elimination of CSCs represents an effective strategy for achieving complete remission of colon cancers, and the identification of CSCs is a key first step.

There are several colon CSC markers, including CD133, CD44, CD166, CD24, and aldehyde dehydrogenase 1 (ALDH1) [45]. Among these, CD133 was the first identified as a cancer-initiating marker or CSC marker when a $\mathrm{CD}_{133^{+}}$subpopulation was found to be tumorigenic in a serial xenograft assay in nude mice [5]. Clinically, higher levels of CD133 expression have been associated with a poor prognosis for advanced colon cancer patients, and this has supported the significance of CD133 expression in colon cancer [46]. CD133 ${ }^{+}$cell populations from tumors have also been found to express CD44. The stem-like epithelial specific $\mathrm{CD}_{4} 4^{+}$cells indicates that CD44 represents another marker of colon CSCs [8]. In the present study, when $\mathrm{CD}_{133^{+}}$or $\mathrm{CD} 44^{+}$cells were labeled, they were found to be more than $90 \%$ of total cells in both cell lines (data not shown), and more than $70 \%$ of cells were $\mathrm{CD} 133^{+} \mathrm{CD} 44^{+}$double-labeled in these cell lines. When these double-positive cells were injected subcutaneously into nude mice $\left(1.0 \times 10^{4}\right.$ cells/mouse $)$, a model which has provided a reliable and sensitive in vivo system for the study of human colon CSCs, $100 \%$ of the mice developed tumors. Similarly, in a previous study, only the $\mathrm{CD} 133^{+} \mathrm{CD} 44^{+}$population exhibited tumorigenicity compared to the $\mathrm{CD} 133^{-} \mathrm{CD} 44^{-}, \mathrm{CD} 133^{+} \mathrm{CD} 44^{-}$, and $\mathrm{CD} 133^{-} \mathrm{CD} 44^{+}$cells [10]. These results confirmed that the use of multiple markers to identify CSCs is more reliable than the use of only a single marker.

Sasa senanensis leaf extracts, which contain a higher level of phenolics have exhibited immunostimulation-mediated antitumor activity [47], while the antiproliferative and apoptotic effects of Sasa quelpaertensis Nakai have been reported in six human cancer cell lines, including A549, MCF-7, HeG-2, Hela, HCT116, and A375 [48]. Recently, it has also been reported that SQE alone, or in combination with cisplatin exerts anti-CSC and antimetastatic effects in H1299 and A549 human lung cancer cells by inhibiting the phosphorylation of phosphoinositide-3-kinase (PI3K) and by 
activating mammalian target of rapamycin (mTOR) [30]. To the best our knowledge, the present study is the first to demonstrate that SQE mediates an anti-colon cancer stemness effect by suppressing self-renewal, increasing cell differentiation, and inhibiting cell tumorigenicity of the colon CSCs.

In the present study, in vitro clonogenic and sphere formation assays were performed and analyzed the inhibitory effect of SQE on the self-renewal capacity of colon CSCs. The ability of CSCs to form colonies from a single cell, and to maintain anchorage-independent sphere formation in serum-free medium, has been shown to be directly proportional to the number of self-renewal cells present [3]. In the present study, CD $133^{+} \mathrm{CD} 44^{+}$cells isolated from both HT29 and HCT116 cell lines were able to form colonies and spheroids. However, in the presence of SQE, the subsequent formation of colonies and spheres was suppressed. The Wnt/ $\beta$-catenin signaling pathway is critical for promoting the self-renewal capacity of CSCs [18], and aberrant Wnt/ $\beta$-catenin signaling is an early event in most human colorectal cancers [34]. It has also been reported that $\beta$-catenin localized to the nucleus in cells expressing CD133 and CD44 [8]. In the present study SQE down-regulated expression of $\beta$-catenin and decreased phosphorylation of GSK3 $\beta$. Both of these results, support a SQE-mediated effect on colon CSC stemness that is induced via potent inhibitory effect on Wnt/ $\beta$-catenin signaling. Other natural dietary compounds, including curcumin and turmeric have also been shown to attenuate the self-renewal capacity of colon cancer cells via $\beta$-catenin signaling through to Wnt-3a [49]. Similarly, sulforaphane derived from broccoli has been reported to regulate the Wnt/ $\beta$-catenin self-renewal pathway [50].

Furthermore, SQE treatment enhanced the differentiation of $\mathrm{CD} 133^{+} \mathrm{CD} 44^{+}$cells by upregulating the colonic epithelial differentiation marker, CK20. In addition, HCT116 cells have been characterized as not very differentiated and a highly aggressive cell line. In contrast, HT29 cells appear to possess some capacity for differentiating into enterocytes and mucin-expressing cell types [51]. However, for both cell lines in the present study, SQE treatment resulted in the up-regulation of the differentiation marker, CK20. Not many studies have shown the efficacy of naturally occurring dietary compounds on the differentiation of colon CSCs. Omega-3 eicosapentaenoic acid (EPA) has been shown to decrease levels of CD133 ${ }^{+}$colon CSCs by upregulating CK20 [52], and a carotenoid present in orange colored vegetables, $\beta$-carotene, has also been shown to induce the neuronal differentiation of human neuroblastoma cells [53]. Highly expressed stem cell markers, including DLK1, Notch1, and Sox-2, are also important for stem cell characteristics. In the present study, the downregulation of these CSC markers by SQE was associated with the suppression of CSC maintenance. In the present study, expressions levels of DLK1, Notch1, and Sox-2 were significantly down-regulated following treatment with SQE both in vitro and in vivo.

In vivo, SQE supplementation (300 $\mathrm{mg} / \mathrm{kg}$ b.w.) was found to weakly inhibit colon tumor growth, yet it significantly suppressed the expression of CSC markers, Wnt/ $\beta$-catenin signaling, and HIF- $1 \alpha$ signaling in the tumors that formed. Previously, administration of SQE at $300 \mathrm{mg} / \mathrm{kg}$ b.w. every day for seven weeks suppressed dextran sulfate sodium (DSS)-induced colitis in a mouse model [54]. For patients with inflammatory bowel disease, such as ulceritive colitis, the chronic inflammatory state of these patients is considered to be a contributing factor to the development of colorectal cancer [55]. Based on the present results, it is possible that treatment with $300 \mathrm{mg} / \mathrm{kg} \mathrm{b.w.} \mathrm{SQE} \mathrm{may} \mathrm{prevent}$ chronic inflammation in the early stages of colon cancer, yet may not be sufficient to inhibit tumor growth, especially the growth of more malignant CSCs. Thus, it is possible that a higher dose may be 
required for the latter compared with the former. Further clinical study is warranted to confirm the present results.

Other bio-active compounds have been derived from leaves of the Sasa species. For example, lignin and polysaccharides from the Sasa species have been reported to exhibit anti-tumor activity [56], and Sasa Health extracts containing polysaccharides, cholorophyllin, lignin, and flavonoids have exhibited an anti-tumor effect in Her2/NeuN mice [24]. Many phytochemicals mediate strong antioxidant activity and anti-inflammatory effects by suppressing either the initiation or promotion step of carcinogenesis [57]. SQE contains various polyphenols, including $p$-coumaric acid and tricin, which regulate the metabolic activation of potential carcinogens and are recognized by xenobiotic metabolizing enzymes [25,58]. Previously, it was reported that $p$-coumaric acid and tricin, bio-active compounds in SQE, exerted anti-inflammatory effects in a lipopolysaccharide-stimulated inflammatory model of intestinal epithelial Caco-2 cells co-cultured with RAW 264.7 macrophage cells [54]. However, the effects observed for these two compounds were less than the effects observed following treatment with SQE. Similarly, in the present study, $p$-coumaric acid and tricin suppressed self-renewal capacity, induced cell differentiation, and down-regulated the expression of various stem cell markers, less effectively than SQE. Furthermore, the combined treatment of $p$-coumaric acid and tricin had less effect on the suppression of sphere formation and stem cell marker expression, thereby confirming that other components of SQE are necessary for mediating the anti-CSC effects of SQE. These observations are consistent with those of previous studies where additive or synergistic effects of combined nutrients have been reported [59,60]. For example, the antioxidant activities of lycopene and other carotenoids from tomatoes have been found to be synergistic in protecting liposomes from oxidation compared with each carotenoid individually [61]. For the additive and synergistic antioxidant and anti-cancer activities of phytochemicals found in fruits and vegetables, these have been attributed to the complex mixture of these phytochemicals in whole foods [62]. Correspondingly, SQE, which includes a combination of polyphenols, has the potential to mediate additive anti-CSC effects in colon cancer.

\section{Experimental Section}

\subsection{Preparation of $S Q E$}

SQE was prepared as previously described [54]. Briefly, harvested Sasa quelpaertensis Nakai bamboo leaves $\left(1 \mathrm{~kg}\right.$ ) from Mt. Halla on Jeju Island in South Korea were cleaned and dried at $60{ }^{\circ} \mathrm{C}$. The dried leaves were then extracted with $70 \%$ ethanol at room temperature. After $48 \mathrm{~h}$, the SQE was filtered and concentrated using a rotary evaporator under reduced pressure, then was freeze-dried and ground into a powder. This SQE was stored at $-20{ }^{\circ} \mathrm{C}$ until needed. The two major compounds in $\mathrm{SQE}$ are $p$-coumaric acid and tricin, and the concentrations of these compounds were determined using high performance liquid chromatography (HPLC) 2695 Alliance System (Waters Corp., Milford, MA, USA). The concentrations of $p$-coumaric acid and tricin were 1.13 and $0.82 \mathrm{mg} / \mathrm{g}$, respectively [54]. 


\subsection{Cell Culture}

The human colon cancer cell lines, HT29 and HCT116, were purchased from American Type Culture Collection (ATCC, Rockville, MD, USA) and were cultured in McCoy's 5A medium (Welgene, Daegu, Korea) supplemented with 10\% fetal bovine serum (FBS) (Hyclone, Logan, UT, USA) and $1 \%$ penicillin-streptomycin $(100 \mathrm{U} / \mathrm{mL}$ and $100 \mu \mathrm{g} / \mathrm{mL}$, respectively) (Invitrogen, Carlsbad, CA, USA). The cells were maintained at $37^{\circ} \mathrm{C}$ in a humidified $5 \% \mathrm{CO}_{2}$ environment.

\subsection{Isolation of CD $133^{+} \mathrm{CD} 44^{+}$CSCs Using a Fluorescence-Activated Cell Sorting (FACS) System}

Expression of the CSC markers, CD133 and CD44, were detected using flow cytometry. Briefly, HT29 and HCT116 cells were harvested with $0.05 \%$ trypsin and were washed with phosphate buffered saline (PBS). An Alexa Fluor 488 conjugated CD44 monoclonal antibody (Cell Signaling, Danvers, MA, USA) and a CD133 monoclonal antibody (Miltenyi Biotec, Bergisch Gladbach, Germany) were incubated with cells in the dark at $4{ }^{\circ} \mathrm{C}$. After $30 \mathrm{~min}$, the cells were washed and analyzed by a FACS DiVa system (BD, San Jose, CA, USA). Twenty percent of the cells with the highest fluorescence levels and the lowest fluorescence levels were selected as positive and negative controls, respectively.

\subsection{Clonogenic Assays}

To evaluate the self-renewal characteristics of the isolated colon CSCs, clonogenic assays were performed as previously described [14]. Briefly, CD133 ${ }^{+} \mathrm{CD} 44^{+}$HT29 and HCT116 cells were plated in 6-well plates (300 cells/well) and then were treated with $\operatorname{SQE}(0,100,200$, or $300 \mu \mathrm{g} / \mathrm{mL})$, or comparable doses of $p$-coumaric acid and tricin. After 8 days, the colonies were fixed with $0.9 \% \mathrm{NaCl}$ and were stained with crystal violet (Sigma Aldrich, St. Louis, MO, USA). At least 50 stained colonies were counted. Plating efficiency (PE) was calculated as follows: $\mathrm{PE}=$ (number of colonies/number of seeded cells) $\times 100 \%$ [14].

\subsection{Sphere Formation Assays}

Another assay to determine the self-renewal capacity of colon CSCs, sphere formation assay was performed as previously described [14]. Briefly, 6-well plates were coated with a $10 \%$ stock solution of poly-(2-hydroxyethyl methacrylate) (polyHEMA; Sigma Aldrich). Sphere medium was then added to each well [1:1 DMEM/F-12 medium (Welgene)] that was supplemented with 2\% B27 (Invitrogen), $20 \mathrm{ng} / \mathrm{mL}$ human epidermal growth factor (EGF, Pepro Tech, London, UK), and $40 \mathrm{ng} / \mathrm{mL}$ basic fibroblast growth factor (bFGF, Pepro Tech). CD133 ${ }^{+} \mathrm{CD} 44^{+}$HT29 and HCT116 cells $\left(8 \times 10^{4}\right.$ cells/well) were treated with SQE $(0,100,200$, or $300 \mu \mathrm{g} / \mathrm{mL}), p$-coumaric acid, and tricin. After 8 days, the number of spheres containing more than 50 cells were counted and photographed.

\subsection{Antibodies and Western Blot Assays}

Western blot assays were performed as previously described [53]. Briefly, cells and tumor tissues were lysed in RIPA buffer. Nuclear extracts was obtained using hypotonic and hypertonic buffer. These lysates and nuclear extracts were then separated by sulfate-polyacylamide gel electrophoresis 
(SDS-PAGE) and transferred onto polyvinylidene fluoride (PVDF) membranes (Millipore, Billerica, MA, USA). The membranes were incubated with 5\% non-fat dried milk, and then were incubated overnight at $4{ }^{\circ} \mathrm{C}$ with primary antibodies raised against cytokeratin 20 (CK20, Abcam, Cambridge, MA, USA), DLK1, Sox-2, CD133 (Millipore), Notch1, HIF-1 $\alpha$ (Novus Biologicals, Littleton, CO, USA), $\beta$-catenin, VEGF (Santa Cruz Biotechnology, Santa Cruz, CA, USA), CD44, Lamin A/C, or phospho GSK3 $\beta$ (Cell Signaling Technology, Danvers, MA, USA). The membranes were subsequently incubated with the appropriate secondary horseradish peroxidase IgGs, and bound antibodies were detected using enhanced chemiluminescence reagents (Animal Genetics Inc., Suwon, Kyonggi-do, Korea). Detection of $\alpha$-tubulin (Sigma Aldrich) was used as a loading control.

\subsection{Real-Time Quantitative PCR}

Total cellular RNA was extracted using Trizol reagent (Invitrogen), and cDNA was synthesized using a RevertAid First Strand cDNA Synthesis Kit (Thermo Fisher Scientific, Waltham, MA, USA). PCR amplification was performed using Taq polymerase (TAKARA, Tokyo, Japan). Real-time PCR was performed using a Rotor-Gene Q instrument (Qiagen, Austin, TX, USA). Samples were combined with a Power SYBR Green PCR Master Mix (Qiagen, Hilden, Germany) and were subjected to the following conditions: initiation at $95{ }^{\circ} \mathrm{C}$ for $5 \mathrm{~min}$, denaturation at $95{ }^{\circ} \mathrm{C}$ for $5 \mathrm{~s}$, annealing at $60{ }^{\circ} \mathrm{C}$ for $10 \mathrm{~s}$, and extension at $72{ }^{\circ} \mathrm{C}$ for $10 \mathrm{~s}$. All data were normalized to the expression levels detected for $\beta$-actin and were analyzed by the CT method. The primers used included as follows: 5'-TGG ATG CAG AAC TTG ACA ACG T-3' (forward) and 5'-ATA CCT GCT ACG ACA GTC GTG GT-3' (reverse) for human CD133; 5'-GAG GCG TGG CAG ACT ATG C-3' (forward) and 5'-CTT GTA CTC CGT CAG CGT GA-3' (reverse) for human Notch1; 5'-AGCA CCC ATG GCA GAA GG-3' (forward) and 5'-CTC GAT TGG ATG GCA GTA CT-3' (reverse) for human VEGF; 5'-CCA ATG CCT TTG ATG GAC C-3' (forward) and 5'-TCT GTC TGT GCT GTC GGT GAT-3' (reverse) for human CD44; 5'-ATT GGC AAT GAG CGG TTC-3' (forward) and 5'-GGA TGC CAC AGG ACT CCA T-3' (reverse) for $\beta$-actin.

\subsection{In Vivo Tumor Xenograft Model}

Five-week-old male BALB/c nude mice (weight: 20-22 g) were purchased (Central Lab, Animal Inc., Seoul, Korea) and maintained under pathogen-free conditions (Ewha Laboratory Animal Genomic Center, Ewha Womans University, Seoul, Korea). Body weight (b.w.) and food intake were recorded twice a week.

To examine tumorigenicity of $\mathrm{CD} 133^{+} \mathrm{CD} 44^{+}$double stained HT29 cells $\left[1 \times 10^{4}\right.$ cells $(n=4)$ and $1 \times 10^{5}$ cells $\left.(n=6)\right]$ suspended in growth factor-reduced matrigel (BD Bioscience Laboratory, Bedford, MA, USA) were subcutaneously injected in the right flank of the BALB/c nude mice. These mice were sacrificed three weeks after injection and the tumorigenicity was examined.

To examine the effect of SQE on tumorigenicity, mice were randomly allocated into two groups (14 animals per group), (1) tumor control group (Ctrl) that received a standard diet and (2) SQE group (SQE) that received an oral supplement of $300 \mathrm{mg} / \mathrm{kg}$ b.w. SQE in distilled water. The latter group received SQE supplements five days a week for nine weeks. On day 14 of the SQE supplementation regimen, the mice were subcutaneously injected with $1 \times 10^{4} \mathrm{CD} 133^{+} \mathrm{CD} 44^{+}$double-stained HT29 
cells suspended in growth factor-reduced matrigel (BD Bioscience Laboratory, Bedford, MA, USA) into the right flank region. Tumor volume was measured twice a week using a digital caliper and was calculated as follows: (volume $=$ length $\left.(\mathrm{mm}) \times \operatorname{width}^{2} \cdot\left(\mathrm{mm}^{2}\right) / 2\right)$. Six weeks after the injection of tumor cells, the mice were administered pimonidazole $(60 \mathrm{mg} / \mathrm{kg}$ b.w.) $1 \mathrm{~h}$ prior to sacrifice. Upon resection of each tumors, the size and weight were measured, and then the tumors were immediately immersed in 4\% formaldehyde or were frozen. Animal care and all experimental protocols were approved by the Animal Care and Use Committee of Ewha Womans University (IACUC approval No.: 2014-01-006).

\subsection{Statistical Analysis}

Statistical analyses were performed using GraphPad PRISM software (GraphPad Software, San Diego, CA, USA). The data are presented as the mean \pm standard error of the mean (SEM). One-way analysis of variance (ANOVA) followed by Tukey's post hoc test was used to analyze the five groups that were included in the in vitro study, while Student's $t$-test was used to estimate differences between two groups included in the in vivo study. A $p$-value less than 0.05 was considered statistically significant.

\section{Conclusions}

In summary, SQE treatment inhibited colon CSCs both in vitro and in vivo by inducing cell differentiation, by suppressing tumorigenesis and the expression of CSC markers such as CD133, CD44, DLK1, Notch1, and Sox-2, and by regulating components of the Wnt/ $\beta$-catenin and hypoxia related HIF-1 $\alpha$ signaling pathways. These findings suggest that SQE may be a highly effective therapeutic strategy for controlling the growth of human malignant colon cancer cells.

\section{Acknowledgments}

This work was supported by the Cooperative Research Program for Agriculture Science \& Technology Development (Project No. PJ009777).

\section{Author Contributions}

All of the authors significantly contributed to this manuscript as follows: Soo Jin Min performed the experiments, analyzed the data, and wrote the draft manuscript. Ji Ye Lim performed experiments and analyzed the data. Haeng Ran Kim and Se-Jae Kim contributed to the study design and the interpretation of the data. Yuri Kim planned and designed the study and contributed to the writing of the manuscript. All of the authors have read and approved the final manuscript.

\section{Abbreviations}

ALDH1: Aldehyde dehydrogenase 1; bFGF: Basic fibroblast growth factor; CSC: Cancer stem cell; CK20: Cytokeratin 20; DLK1: Delta like 1 homologue; DMBA: 7,12-Dimethylbenz[ $\alpha]$ anthracene; DSS: Dextran sulfate sodium; EGF: Epidermal growth factor; EPA: Eicosapentaenoic acid; FACS: Flow-activated cell sorting; GSK3 $\beta$ : Glycogen synthase kinase-3 $\beta$; HEMA: Hydroxyethyl methacylate; HIF-1: Hypoxia-inducible factor-1; HPLC: High performance liquid chromatography; mTOR: Mammalian target of rapamycin; Notch1: Notch homolog 1, translocation-associated (Drosophila); 
PBS: Phosphate buffered saline; P.C: P-coumaric acid; PE: Plating efficiency; PI3K: Phosphorylation of phosphoinositide-3-kinase; PVDF: Polyvinylidene fluoride; Sox-2: SRY-related HMG-box-2; SQE: Sasa quelpaertensis leaf extract; T: Tricin; TCF/LEF: T cell factor/lymphoid enhancer factor; VEGF: Vascular endothelial growth factor.

\section{Conflicts of Interest}

The authors declare no conflict of interest.

\section{References}

1. Ferlay, J.; Ervik, M.; Dikshit, R.; Eser, S.; Mathers, C.; Rebelo, M.; Parkin, D.M.; Forman, D.; Bary, F. Cancer Incidence and Mortality Worldwide: Iarc Cancer Base; International Agency for Research on Cancer: Lyon, France, 2012.

2. Andre, T.; Boni, C.; Mounedji-Boudiaf, L.; Navarro, M.; Tabernero, J.; Hickish, T.; Topham, C.; Zaninelli, M.; Clingan, P.; Bridgewater, J.; et al. Oxaliplatin, fluorouracil, and leucovorin as adjuvant treatment for colon cancer. N. Engl. J. Med. 2004, 350, 2343-2351.

3. Clarke, M.F.; Dick, J.E.; Dirks, P.B.; Eaves, C.J.; Jamieson, C.H.; Jones, D.L.; Visvader, J.; Weissman, I.L.; Wahl, G.M. Cancer stem cells-Perspectives on current status and future directions: Aacr workshop on cancer stem cells. Cancer Res. 2006, 66, 9339-9344.

4. Saigusa, S; Tanaka, K.; Toiyama, Y.; Yokoe, T.; Okugawa, Y.; Ioue, Y.; Miki, C.; Kusunoki, M. Correlation of CD133, OCT4, and SOX2 in rectal cancer and their association with distant recurrence after chemoradiotherapy. Ann. Surg. Oncol. 2009, 16, 3488-3498.

5. O'Brien, C.A.; Pollett, A.; Gallinger, S.; Dick, J.E. A human colon cancer cell capable of initiating tumour growth in immunodeficient mice. Nature 2007, 445, 106-110.

6. Fang, D.D.; Kim, Y.J.; Lee, C.N.; Aggarwal, S.; McKinnon, K.; Mesmer, D.; Norton, J.; Birse, C.E.; He, T.; Ruben, S.M.; et al. Expansion of $\mathrm{CD}_{133^{+}}$colon cancer cultures retaining stem cell properties to enable cancer stem cell target discovery. Br. J. Cancer 2010, 102, 1265-1275.

7. Keysar, S.B.; Jimeno, A. More than markers: Biological significance of cancer stem cell-defining molecules. Mol. Cancer Ther. 2010, 9, 2450-2457.

8. Dalerba, P.; Dylla, S.J.; Park, I.K.; Liu, R.; Wang, X.; Cho, R.W.; Hoey, T.; Gurney, A.; Huang, E.H.; Simeone, D.M.; et al. Phenotypic characterization of human colorectal cancer stem cells. Proc. Natl. Acad. Sci. USA 2007, 104, 10158-10163.

9. Wang, C.; Xie, J.; Guo, J.; Manning, H.C.; Gore, J.C.; Guo, N. Evaluation of CD44 and CD133 as cancer stem cell markers for colorectal cancer. Oncol. Rep. 2012, 28, 1301-1308.

10. Haraguchi, N.; Ohkuma, M.; Sakashita, H.; Matsuzaki, S.; Tanaka, F.; Mimori, K.; Kamohara, Y.; Inoue, H.; Mori, M. CD133 ${ }^{+} \mathrm{CD} 44^{+}$population efficiently enriches colon cancer initiating cells. Ann. Surg. Oncol. 2008, 15, 2927-2933.

11. Trumpp, A.; Wiestler, O.D. Mechanisms of disease: Cancer stem cells-targeting the evil twin. Nat. Clin. Pract. Oncol. 2008, 5, 337-347.

12. Gupta, P.B.; Chaffer, C.L. Weinberg, R.A. Cancer stem cells: Mirage or reality? Nat. Med. 2009, 15, 1010-1012. 
13. Smas, C.M.; Sul, H.S. Pref-1, a protein containing EGF-like repeats, inhibits adipocyte differentiation. Cell 1993, 73, 725-734.

14. Kim Y.; Lin, Q.; Zelterman, D.; Yun, Z. Hypoxia-regulated delta-like 1 homologue enhances cancer cell stemness and tumorigenicity. Cancer Res. 2009, 69, 9271-9280.

15. Graham, V.; Khudyakov, J.; Ellis, P.; Pevny, L. SOX2 functions to maintain neural progenitor identity. Neuron 2003, 39, 749-765.

16. Sikandar, S.S.; Pate, K.T.; Anderson, S.; Dizon, D.; Edwards, R.A.; Waterman, M.L.; Lipkin, S.M. NOTCH signaling is required for formation and self-renewal of tumor-initiating cells and for repression of secretory cell differentiation in colon cancer. Cancer Res. 2010, 70, 1469-1478.

17. Groden, J.; Joslyn, G.; Samowitz, W.; Jones, D.; Bhattacharyya, N.; Spirio, L.; Thliveris, A.; Robertson, M.; Egan, S.; Meuth, M.; et al. Response of colon cancer cell lines to the introduction of $A P C$, a colon-specific tumor suppressor gene. Cancer Res. 1995, 55, 1531-1539.

18. Liu, S.; Dontu, G.; Wicha, M.S. Mammary stem cells, self-renewal pathways, and carcinogenesis. Breast Cancer Res. 2005, 7, 86-95.

19. Clevers, H. Wnt/beta-catenin signaling in development and disease. Cell 2006, 127, 469-480.

20. Kim, Y.; Lin, Q.; Glazer, P.M.; Yun, Z. Hypoxic tumor microenvironment and cancer cell differentiation. Curr. Mol. Med. 2009, 9, 425-434.

21. Brahimi-Horn, C.; Pouyssegur, J. The role of the hypoxia-inducible factor in tumor metabolism growth and invasion. Bull. Cancer 2006, 93, E73-E80.

22. Okabe, S.; Takeuchi, K.; Takagi, K.; Shibata, M. Stimulatory effect of the water extract of bamboo grass (folin solution) on gastric acid secretion in pylorus-ligated rats. Jpn. J. Pharmacol. 1975, 25, 608-609.

23. Yang, J.H.; Lim, H.S.; Heo, Y.R. Sasa borealis leaves extract improves insulin resistance by modulating inflammatory cytokine secretion in high fat diet-induced obese C57/BL6J mice. Nutr. Res. Pract. 2010, 4, 99-105.

24. Ren, M.; Reilly, R.T.; Sacchi, N. Sasa health exerts a protective effect on Her2/NeuN mammary tumorigenesis. Anticancer Res. 2004, 24, 2879-2884.

25. Kang, S.I.; Shin, H.S.; Kim, H.M.; Hong, Y.S.; Yoon, S.A.; Kang, S.W.; Kim, J.H.; Ko, H.C.; Kim, S.J. Anti-obesity properties of a Sasa quelpaertensis extract in high-fat diet-induced obese mice. Biosci. Biotechnol. Biochem. 2012, 76, 755-761.

26. Shibata, M.; Fojii, M.; Yamaguchi, R. [Pharmacological studies on bamboo grass. IV. Toxicological and pharmacological effects of the extract (FIII) obtained from Sasa albomarginata Makino et Shibata (author's trans1)] (in Japanese). Yakugaku Zasshi 1979, 99, 663-668.

27. Kitamura, K.; Saitoh, T.; Matsuo, A.; Suyama, Y. Development of microsatellite markers for the dwarf bamboo species Sasa cernua and Sasa kurilensis (Poaceae) in northern japan. Mol. Ecol. Resour. 2009, 9, 1470-1472.

28. Seki, T.; Maeda, H. Cancer preventive effect of kumaizasa bamboo leaf extracts administered prior to carcinogenesis or cancer inoculation. Anticancer Res. 2010, 30, 111-118.

29. Tsunoda, S.; Yamamoto, K.; Sakamoto, S.; Inoue, H.; Nagasawa, H. Effects of Sasa Health, extract of bamboo grass leaves, on spontaneous mammary tumourigenesis in SHN mice. Anticancer Res. 1998, 18, 153-158. 
30. Kim, M.; Kim, Y.S.; Kim, K.M.; Ko, H.C.; Kim, S.J.; Kim, J.H.; Kim, Y. Combination of Sasa quelpaertensis Nakai leaf extract and cisplatin suppresses the cancer stemness and invasion of human lung cancer cells. Integr. Cancer Ther. 2014, 13, 529-540.

31. An, S.M.; Lee, S.I.; Choi, S.W.; Moon, S.W.; Boo, Y.C. p-Coumaric acid, a constituent of Sasa quelpaertensis Nakai, inhibits cellular melanogenesis stimulated by alpha-melanocyte stimulating hormone. Br. J. Dermatol. 2008, 159, 292-299.

32. Byun, K.M. Apoptotic effect of Sasa quelpaertensis Nakai human colon cancer HT29. J. Life Sci. 2014, 24, 1012-1018.

33. Hemmati, H.D.; Nakano, I.; Lazareff, J.A.; Masterman-Smith, M.; Geschwind, D.H.; Bronner-Fraser, M.; Kornblum, H.I. Cancerous stem cells can arise from pediatric brain tumors. Proc. Natl. Acad. Sci. USA 2003, 100, 15178-15183.

34. Vermeulen, L.; de Sousa, E.M.F.; van der Heijden, M.; Cameron, K.; de Jong, J.H.; Borovski, T.; Tuynman, J.B.; Todaro, M.; Merz, C.; Rodermond, H.; et al. Wnt activity defines colon cancer stem cells and is regulated by the microenvironment. Nat. Cell Biol. 2010, 12, 468-476.

35. Liu, C.; Li, Y.; Semenov, M.; Han, C.; Baeg, G.H.; Tan, Y.; Zhang, Z.; Lin, X.; He, X. Control of beta-catenin phosphorylation/degradation by a dual-kinase mechanism. Cell 2002, 108, 837-847.

36. Pap, M.; Cooper, G.M. Role of glycogen synthase kinase-3 in the phosphatidylinositol 3-kinase/Akt cell survival pathway. J. Biol. Chem. 1998, 273, 19929-19932.

37. Chen, K.L.; Pan, F.; Jiang, H.; Chen, J.F.; Pei, L.; Xie, F.W.; Liang, H.J. Highly enriched $\mathrm{CD} 133^{+} \mathrm{CD} 44^{+}$stem-like cells with $\mathrm{CD} 133^{+} \mathrm{CD} 44^{\text {high }}$ metastatic subset in HCT116 colon cancer cells. Clin. Exp. Metastasis 2011, 28, 751-763.

38. Guruvayoorappan, C.; Kuttan, G. Beta-carotene inhibits tumor-specific angiogenesis by altering the cytokine profile and inhibits the nuclear translocation of transcription factors in $\mathrm{B} 16 \mathrm{~F}-10$ melanoma cells. Integr. Cancer Ther. 2007, 6, 258-270.

39. Das, B.; Tsuchida, R.; Malkin, D.; Koren, G.; Baruchel, S.; Yeger, H. Hypoxia enhances tumor stemness by increasing the invasive and tumorigenic side population fraction. Stem Cells $\mathbf{2 0 0 8}$, $26,1818-1830$.

40. Jogi, A.; Ora, I.; Nilsson, H.; Lindeheim, A.; Makino, Y.; Poellinger, L.; Axelson, H.; Pahlman, S. Hypoxia alters gene expression in human neuroblastoma cells toward an immature and neural crest-like phenotype. Proc. Natl. Acad. Sci. USA 2002, 99, 7021-7026.

41. Couvelard, A.; O’Toole, D.; Turley, H.; Leek, R.; Sauvanet, A.; Degott, C.; Ruszniewski, P.; Belghiti, J.; Harris, A.L.; Gatter, K.; et al. Microvascular density and hypoxia-inducible factor pathway in pancreatic endocrine tumours: Negative correlation of microvascular density and vegf expression with tumour progression. Br. J. Cancer 2005, 92, 94-101.

42. Saunders, M.; Iveson, T. Management of advanced colorectal cancer: State of the art. Br. J. Cancer 2006, 95, 131-138.

43. Jemal, A.; Siegel, R.; Ward, E.; Hao, Y.; Xu, J.; Murray, T.; Thun, M.J. Cancer statistics, 2008. CA Cancer J. Clin. 2008, 58, 71-96.

44. Boman, B.M.; Wicha, M.S. Cancer stem cells: A step toward the cure. J. Clin. Oncol. 2008, 26, 2795-2799.

45. Todaro, M.; Francipane, M.G.; Medema, J.P.; Stassi, G. Colon cancer stem cells: Promise of targeted therapy. Gastroenterology 2010, 138, 2151-2162. 
46. Li, C.Y.; Li, B.X.; Liang, Y.; Peng, R.Q.; Ding, Y.; Xu, D.Z.; Zhang, X.; Pan, Z.Z.; Wan, D.S.; Zeng, Y.X.; et al. Higher percentage of $\mathrm{CD}_{133^{+}}$cells is associated with poor prognosis in colon carcinoma patients with stage IIIb. J. Transl. Med. 2009, 7, 56, doi:10.1186/1479-5876-7-56.

47. Seki, T.; Kida, K.; Maeda, H. Immunostimulation-mediated anti-tumor activity of bamboo (Sasa senanensis) leaf extracts obtained under "vigorous" condition. Evid. Based Complement. Altern. Med. 2010, 7, 447-457.

48. Kim J.H.; Kim, K.M. Antiproliferative and apoptotic effects of Sasa quelpaertensis Nakia in human cancer cells. J. Life Sci. 2014, 24, 903-909.

49. Ryu, M.J.; Cho, M.; Song, J.Y.; Yun, Y.S.; Choi, I.W.; Kim, D.E.; Park, B.S.; Oh, S. Natural derivatives of curcumin attenuate the Wnt/beta-catenin pathway through down-regulation of the transcriptional coactivator p300. Biochem. Biophys. Res. Commun. 2008, 377, 1304-1308.

50. Li, Y.; Zhang, T.; Korkaya, H.; Liu, S.; Lee, H.F.; Newman, B.; Yu, Y.; Clouthier, S.G.; Schwartz, S.J.; Wicha, M.S.; et al. Sulforaphane, a dietary component of broccoli/broccoli sprouts, inhibits breast cancer stem cells. Clin. Cancer Res. 2010, 16, 2580-2590.

51. Demers, M.J.; Thibodeau, S.; Noel, D.; Fujita, N.; Tsuruo, T.; Gauthier, R.; Arguin, M.; Vachon, P.H. Intestinal epithelial cancer cell anoikis resistance: EGFR-mediated sustained activation of Src overrides Fak-dependent signaling to MEK/Erk and/or PI3-K/Akt-1. J. Cell. Biochem. 2009, 107, 639-654.

52. De Carlo, F.; Witte, T.R.; Hardman, W.E.; Claudio, P.P. Omega-3 eicosapentaenoic acid decreases CD133 colon cancer stem-like cell marker expression while increasing sensitivity to chemotherapy. PLoS ONE 2013, 8, e69760.

53. Lee, H.A.; Park, S.; Kim, Y. Effect of $\beta$-carotene on cancer cell stemness and differentiation in SK-N-BE(2)C neuroblastoma cells. Oncol. Rep. 2013, 30, 1869-1877.

54. Kim, K.M.; Kim, Y.S.; Lim, J.Y.; Min, S.J.; Ko, H.C.; Kim, S.J.; Kim, Y. Intestinal anti-inflammatory activity of Sasa quelpaertensis leaf extract by suppressing lipopolysaccharide-stimulated inflammatory mediators in intestinal epithelial Caco-2 cells co-cultured with RAW 264.7 macrophage cells. Nutr. Res. Pract. 2015, 9, 3-10.

55. Toll, A.D.; Boman, B.M.; Palazzo, J.P. Dysplastic lesions in inflammatory bowel disease show increased positivity for the stem cell marker aldehyde dehydrogenase. Hum. Pathol. 2012, 43, 238-242.

56. Suzuki, S.; Saito, T.; Uchiyama, M.; Akiya, S. Studies on the anti-tumor activity of polysaccharides. I. Isolation of hemicelluloses from yakushima-bamboo and their growth inhibitory activities against sarcoma-180 solid tumor. Chem. Pharm. Bull. 1968, 16, 2032-2039.

57. Surh, Y.J. Cancer chemoprevention with dietary phytochemicals. Nat. Rev. Cancer 2003, 3, 768-780.

58. Zhao, M.; Yang, B.; Wang, J.; Liu, Y.; Yu, L.; Jiang, Y. Immunomodulatory and anticancer activities of flavonoids extracted from litchi (Litchi chinensis Sonn.) pericarp. Int. Immunopharmacol. 2007, 7, 162-166.

59. Mates, J.M.; Segura, J.A.; Alonso, F.J.; Marquez, J. Natural antioxidants: Therapeutic prospects for cancer and neurological diseases. Mini Rev. Med. Chem. 2009, 9, 1202-1214. 
60. Mates, J.M.; Segura, J.A.; Alonso, F.J.; Marquez, J. Anticancer antioxidant regulatory functions of phytochemicals. Curr. Med. Chem. 2011, 18, 2315-2338.

61. Shi, J.; Kakuda, Y.; Yeung, D. Antioxidative properties of lycopene and other carotenoids from tomatoes: Synergistic effects. Biofactors 2004, 21, 203-210.

62. Liu, R.H. Health benefits of fruit and vegetables are from additive and synergistic combinations of phytochemicals. Am. J. Clin. Nutr. 2003, 78, 517S-520S.

(C) 2015 by the authors; licensee MDPI, Basel, Switzerland. This article is an open access article distributed under the terms and conditions of the Creative Commons Attribution license (http://creativecommons.org/licenses/by/4.0/). 